\title{
DESENVOLVENDO O CUIDADO PROPOSTO POR LEININGER COM UMA PESSOA EM TERAPIA DIALİTICA*
}

\author{
DEVELOPING THE CARE PROPOSED BY LEININGER \\ WITH A PERSON IN DIALYSIS TREATMENT
}

\section{DESARROLLANDO EL CUIDADO INDICADO POR LEININGER COM UNA PERSONA EN TERAPLA DIALITICA}

\author{
Maria Socorro de Araújo Dias** \\ Thelma Leite de Araujo*** \\ Maria Grasiela Teixeira Barroso****
}

Dias MSA, Araujo TL, Barroso, MGT. Desenvolvendo o cuidado proposto por Leininger com uma pessoa em terapia dialítica. Rev Esc Enferm USP 2001; 35(4): 354-60.

\begin{abstract}
RESUMO
Estudo de abordagem etnográfica, tipo estudo de caso. Descreve o acompanhamento de uma pessoa portadora de insuficiência renal crônica, com déficit de adesão ao tratamento. O embasamento teórico foi o modelo SUNRISE proposto por Leininger. Apresenta-se o Sr. Luz e descrevem-se os cenários. Observam-se influências sócio-econômicas, culturais, tecnológicas e educacionais no processo de cuidar. Após a identificação dos sistemas de saúde, decidiram-se as ações do cuidar através da manutenção, acomodação e reestruturação. O estudo possibilitou intervenções efetivas para os comportamentos de não aderência. O referencial é oportuno em processos contínuos de cuidado, favorecidos pela proximidade entre enfermeira e pessoa assistida.
\end{abstract}

PALAVRAS-CHAVE: Enfermagem. Cuidados de enfermagem. Hemodiálise.

\begin{abstract}
Study of a ethnographic approach, type case study. Describing a person's bearer of chronic renal inadequacy accompaniment, with adhesion deficit to the treatment. The theoretical presupposition had the model SUNRISE proposed by Leininger. It's presented the Mr. Light and the involved sceneries. Described. Influences economical, social, cultural, technological and educational in the process of taking care. After the identification of the systems of health, were decided the actions of taking care through the maintenance, accommodation and restoration. The study possibilited effective interventions for the behaviors of non adherence. The referencial in continuous and lingering processes of care, favoured by the proximity between nurse and attended person.
\end{abstract}

KEYWORDS: Nursing. Nursing care. Haemodialysis.

\section{RESUMEN}

Estudio de abordaje etnográfica, tipo estudio de caso. Describe el acompanhamiento de una persona portadora de insuficiência renal cronica com déficit de adhesión al tratamiento. La base teórica fué el modelo SUNRISE propuesto por Leininger. Presentase el senor Luz e se describen los escenarios. Observase influencias socio-económicas, culturales, tecnológicas e educacionales en el procedimiento de cuidar. Después de la identificatión los sistemas de salud, se decidió las acciones del cuidar a través del mantenimiento, acomodación y reestructuración. El estudio permitió efectivas intervenciones para los comportamientos de no adhesión. El referencial es oportuno en procesos continuos de cuidado, favorecidos por la proximidad entre enfermera $y$ persona asistida.

PALABRAS-CLAVE : Enfermería. Atencion de enfermería. Hemodiálise.

\footnotetext{
Estudo realizado na disciplina Enfermagem Clínica e Cirúrgica do Curso de Mestrado em Enfermagem da Universidade Federal do Ceará - UFC (1999/2000).

** Enfermeira do Centro de Nefrologia da Santa Casa de Sobral. Especialista em Nefrologia. Professora do Curso de Enfermagem da Universidade Estadual Vale do Acaraú. Doutoranda em Enfermagem Clínica e Cirúrgica pela UFC.

*** Enfermeira. Doutora em Enfermagem. Professora do Departamento de Enfermagem da UFC.

**** Enfermeira. Doutora. Professora Emérita do Departamento de Enfermagem da UFC.
} 


\section{INTRODUÇÃO}

A Insuficiência Renal Crônica (IRC) que foi a responsável por muitos óbitos, continua ainda com índices altos de morbi-mortalidade. Se por um lado ocorreu um considerável avanço técnico-científico quanto às modalidades de terapias de substituição da função renal, por outro lado, as clínicas existentes (especialmente no Brasil ) são insuficientes para atender a demanda das pessoas com IRC. Acredita-se, até, ainda existirem óbitos por falta de assistência, e em algumas vezes, até por desconhecimento do tratamento, conforme informou ${ }^{(1)}$.

A incidência de IRC terminal com necessidade de terapia dialítica aumenta anualmente. No Brasil, no ano de 1996, a população de clientes renais crônicos mantida em diálise era de 31.992, com uma prevalência de $204 \mathrm{pmp}$ (pacientes por milhão de pessoa), esta elevou-se em 1997, para 214 pmp (34.061 pacientes), um aumento de $6,47 \%(2)$.

O rim pode ser acometido por diversas enfermidades, sendo que algumas evoluem abruptamente e outras, de forma mais lenta. O resultado final é a presença de múltiplos sinais e sintomas oriundos da incapacidade renal de manter o equilíbrio interno(3). IRC é a perda irreversível da função renal pela destruição progressiva da massa de néfrons ${ }^{(4)}$.

O diagnóstico, seguido do tratamento que é baseado no tripé: diálise, dieta e medicamentos, condiciona o surgimento de complexas alterações que comprometem o aspecto físico e psicológico com repercussões pessoais e sociais(5). Todas estas alterações interferem diretamente na familia, que sofre com as modificações no estilo de vida que se adequa ao período necessário para a realização da diálise e sente diminuídas, assim, as atividades sociais, contando com sentimentos diversos fazendo parte do cenário, tais como: conflitos, frustrações, culpa e depressão(6).

Neste cenário de alterações, Epstein apud Saes(6) afirma que a pessoa é detentora de conhecimentos, sentimentos, percepções que são determinados pelo contexto cultural do qual ela é integrante e que as atitudes e comportamentos diante da doença e tratamento variam em função de como ela é como ser humano.

A percepção de que o contexto cultural influencia no modo de ser, de agir, nas formas de cuidar vem sendo explorada pela enfermagem na busca de um cuidado holístico, tendo como precursora Leininger, enfermeira que preconizou ser o cuidado "culturalmente definido, padronizado e expressado"(7), acreditando que esta forma de cuidar é mais satisfatória e gratificante, uma vez que é adaptada ao modo de vida da pessoa.
Desta forma, apresenta-se como oportuna a aplicação da teoria de enfermagem proposta por Leininger, baseada nos pressupostos filosóficos acima mencionados e denominados de Teoria da Diversidade e Universalidade Cultural do Cuidado, para o desenvolvimento do cuidar em enfermagem para com uma pessoa portadora de IRC. O cuidar requer observação direta, experiência participativa e reflexiva. Para Leininger o cuidado pode ser demonstrado através de expressões, ações, padrões, estilo de vida e significados ${ }^{(8)}$.

Leininger propôs um Modelo teórico-conceitual denominado de SUNRISE simbolizado pelo nascer do sol, tendo como conceitos centrais a cultura como componente da Antropologia e cuidado como o componente da enfermagem. Neste modelo vê-se mais do que o como, vê-se também o quando, o que, em que áreas e em que aspectos a teoria se movimenta e que direção se segue(9). Representa, portanto, um guia sistemático para o cuidado de enfermagem, o qual apresenta semelhanças ao processo de enfermagem, o que faz com que eles se equiparem, uma vez que ambos têm como foco o cuidar.

O Modelo de SUNRISE tem como objetivo descobrir, explicar, interpretar e predizer conhecimento do cuidado, bem como desenvolver cuidado de enfermagem culturalmente congruente ${ }^{(10)}$ Este modelo é constituído de quatro níveis, sendo que os três primeiros fornecem subsídios para o planejamento e execução do cuidado, uma vez que envolve o desenvolvimento do conhecimento, embora esta terminologia não seja utilizada por Leininger.

O primeiro nível é constituído pelos componentes interdependentes da estrutura social e visão -de mundo que segundo a autora, nos leva ao estudo do significado, da natureza e dos atributos do cuidado. Incluem-se, nesta fase, idioma, contexto ambiental do cliente, fatores tecnológicos, religiosos, filosóficos, políticos, econômicos, educacionais bem como grau de parentesco, estrutura social, valores e crenças culturais.

O nivel seguinte, baseado no conhecimento do nível anterior, é a aplicação deste conhecimento à situação do cliente em estudo (indivíduo, família, grupo ou instituição ), onde se observa significado e expressões específicas acerca do cuidado e da saúde.

O terceiro nível, permite identificar, caracterizar os valores, crenças, comportamentos populares, profissionais e a enfermagem. Neste nivel, é possivel identificar semelhanças e diferenças ou seja caracteristicas universais e específicas da cultura do cliente em estudo. As atividades desenvolvidas nesse nível são correspondentes à elaboração de diagnósticos de enfermagem.

O quarto nível do modelo é determina as decisões e ações do cuidado, tendo três mods, a saber: preservação/ manutenção cultural do cuidado, 
acomodação/ negociação cultural do cuidado e repadronização/ reestruturação cultural do cuidado.

Embora não fique explicito no modelo SUNRISE uma fase equivalente a de evolução de enfermagem proposta no processo de enfermagem, percebe-se a importância desta para a execução do cuidar em enfermagem. Entretanto, Leininger aborda a evolução nas entrelinhas de seu modelo no momento em que explicita a importância do cuidado de enfermagem de forma continua para determinação dos cuidados apropriados ao modo de vida e padrões de comportamento da cultura objetivando cura, saúde ou bem-estar.

O modelo representa um processo de solução de problemas que, assim como no processo de enfermagem, apresenta como enfoque a pessoa a ser assistida $^{(8)}$.

Optamos, assim, pelo modelo SUNRISE proposto por Leininger para subsidiar o cuidar de cliente portador de IRC submetido à terapia dialítica. Os quatro conceitos básicos expressos na maioria das teorias de enfermagem: homem, ambiente, saúde e enfermagem, não estão todos claros na teoria em estudo, no entanto, eles emergem de seus pressupostos. O homem apresenta-se como provedor de cuidado que sobrevive numa diversidade de cultura, através da capacidade de oferecer a universalidade do cuidado. O ambiente é compreendido como a totalidade de um acontecimento, situação ou experiência. Saúde é entendida como: "um estado de bem-estar, culturalmente definido, valorizado e praticado, que reflete a capacidade que os indivíduos (ou grupos) têm para desempenhar suas atividades diárias em modos de vida culturalmente expressos, benéficos e padronizados"(8)

\section{OBJETIVO}

Descrever, utilizando a abordagem de estudo de caso, inspirado nos princípios da etnografia, o acompanhamento de uma pessoa portadora de insuficiência renal crônica, utilizando-se, como embasamento teórico para a ação do cuidar em enfermagem, o modelo SUNRISE proposto por Leininger.

\section{METODOLOGIA}

Estudo de abordagem etnográfica, de caráter descritivo, tipo estudo de caso. Optou-se por uma abordagem etnográfica por compreender que esta permite uma descrição cultural da situação envolvida, bem como possibilita que as pessoas envolvidas socializem suas idéias e ações de forma espontânea. No que se refere à delimitação por estudo de caso, adotamos o conceito(11), quando diz que o estudo de caso é um dos mais relevantes tipos de pesquisa qualitativa; outros autores acrescentam que este é caracterizado pela profundidade da investigação através da análise e compreensão de forma clara e bem delimitada, podendo ser aplicado a pessoa, grupo, instituição ou outra unidade social ${ }^{(12,13)}$

Presume-se, portanto, que o estudo de caso numa abordagem etnográfica foi oportuna neste estudo com uma pessoa portadora de IRC, durante o período de julho de 1999 a junho de 2000. Os contextos para a investigação foram: albergue e clínica de hemodiálise. Albergue, neste sentido, é a casa onde os clientes que realizam hemodiálise residem no período inter-dialítico, uma vez que as condições financeiras apresentam-se como fatores impeditivos para o ir e vir de sua cidade de origem até a clínica.

A opção por esta pessoa deu-se pelas peculiaridades apresentadas que atendiam às necessidades do estudo: pessoa em tratamento dialítico com déficit de adesão, aceitação em participar do estudo (foi garantido o anonimato de sua identidade, atendendo assim os aspectos éticos da pesquisa) e atender a abordagem teórica- metodológica. Esta proposta se tornou possivel graças aos contatos prolongados com o sujeito do estudo.

A coleta de dados deu-se baseada no modelo OPR (observação - participação - reflexão) ${ }^{(7)}$ fundamentado na observação participante utilizada na antropologia e que é constituída por quatro fases : observação com atividade de escuta, observação com limitada participação, participação com continuada observação e reflexão e reconfirmação dos resultados com o informante. Para tanto, utilizou-se como instrumentos para coleta de dados de forma processual: observação, em seguida observação participante e entrevista que permitiram a aquisição das informações e retorno ao campo na fase de reflexão dos dados, conforme propõe o modelo POR.

A análise dos dados deu-se de acordo com o modelo teórico conceitual de Leininger ( o modelo de SUNRISE).

\section{APRESENTAÇÃO DOS RESULTADOS}

\section{Identificando a pessoa do estudo (Sr. Luz)}

Um senhor de 52 anos, viúvo, pai de três filhos, sendo que dois, ambos do sexo masculino residem na Região Sul do País e a caçula, uma jovem de 18 anos, mora com um tio desde a morte da mãe há quatro anos. No momento, a filha solteira está grávida. Proveniente de uma cidade serrana, encontrava-se, no início do estudo, há 3 anos e dois meses em terapia dialítica. Não estudou em ensino formal, entretanto rabisca apenas o seu nome. Aposentado por invalidez pelo Sistema Previdenciário, recebe mensalmente 01 salário mínimo. Atualmente, reside no albergue 
masculino para pessoas portadoras de IRC. Nos finais de semana, quando vai para a cidade de origem, fica na casa de seus pais. Durante o período que vem realizando o tratamento na clínica, o $\mathrm{Sr}$. Luz vem demonstrando timidez, dificuldade de adesão às orientações, sendo necessário, em determinadas situações, ir pegá-lo no albergue para realizar sessão dialitica, sendo que, às vezes, ele se encontrava dormindo e em outros momentos passeando. No decorrer do estudo, o Sr. Luz demonstrou-se sempre disponivel, acessivel e por vezes buscava diálogo, relatando dificuldades e "confidências".

\section{Descrevendo os cenários: $O$ albergue masculino /O Centro de diálise}

Casa composta por uma área, seguida da "sala da televisão", de onde se inicia o corredor ao lado dos quartos, em número de três. Após estes, encontra-se a cozinha, o olhar alcança mais à frente mais um quarto, este numa dimensão maior aos anteriormente citados. Neste espaço físico, o cotidiano de homens portadores de IRC é compartilhado por uma senhora, gentilmente chamada pelo diminutivo de seu nome e que segundo depoimentos é "uma mãezona para todos". Sr. Luz costuma sentar-se na calçada, às vezes prefere ficar ao lado, sentado nos bancos da sorveteria. Homem de poucas palavras, mantém um relacionamento satisfatório com os colegas.

No centro de diálise, Sr.Luz é quase sempre uma das últimas pessoas a iniciar o tratamento. Tranqüilo, permite que os demais iniciem logo o tratamento. Enquanto aguarda a sua vez, caminha pelo extenso corredor que dá acesso às três salas de diálise. Conversa, brinca, sorri com os funcionários da copa. Por vezes, prefere esperar o horário da diálise no próprio albergue, necessitando ser "convocado". Sr. Luz dialisa na sala branca, por não ser portador de virus de hepatite. Esta é a maior sala de que o centro dispõe, dialisando 18 pessoas por turno. Sr. Luz dialisa às segundas, quartas e sextas-feiras no terceiro turno que se inicia por volta das 16 horas.

\section{DISCUSSÃO DOS RESULTADOS BASEADOS NO MODELO TEÓRICO CONCEITUAL DE LEININGER}

\section{Visão de mundo do Sr. Luz e as influências de fatores nos padrões de cuidado:}

É válido ressaltar que a estrutura social e cultural e visão de mundo exercem influência no cuidado à saúde e que os fatores constituintes desta estrutura, interagem de forma mútua, caracterizando, assim, a dinâmica do sistema.

Em relação à influência do fator econômico, observa-se que ele exerce um papel importante no adoecer do cliente, uma vez que a doença o atingiu no auge de sua produtividade. Sua atividade anterior era ser banqueiro de engenho, sem vínculo empregatício, com remuneração de acordo com a produção de rapadura, o que naquele momento era um bom negócio, uma vez que gostava muito do que fazia e dava-lhe o rendimento médio de aproximadamente três salários minimos. Atualmente, a renda do Sr. Luz é um salário mínimo recebido através da Previdência Social, como subsídio pela "invalidez" ocasionada pela doença, A esta aposentadoria soma-se uma ajuda não quantificada do filho solteiro que mora no Sul. Entretanto Sr. Luz divide sua renda com a filha, para ajudar em suas despesas.

O fato de não poder exercer atividade empregatícia é muito forte para o Sr. Luz, que chegou a caracterizar doença como: "o fato de não poder trabalhar, fora isso eu não me considero doente". Esta situação financeira parece interferir, ora positivamente, ora negativamente no seu viver, conforme declarou: "se por um lado eu só posso ir em casa de 15 em 15 dias, mas também eu gosto de ficar no albergue, lá só tem amigo".

Sua declaração é melhor compreendida a partir da análise dos fatores sociais e de parentesco realizada de acordo com a observação e outros depoimentos. Diante do impacto do diagnóstico e tratamento, o Sr. Luz viu-se afastado da família, uma vez que necessita dirigir-se ao centro de diálise três vezes por semana para realizar o procedimento dialítico e pela distância que separa sua cidade de origem até o centro de tratamento (em torno de 100 $\mathrm{Km})$. A alternativa apresentada pelo centro e acatada por Sr. Luz foi morar no albergue, destinado pelo centro para clientes portadores de IRC.

Residir no albergue, no período interdialítico, a princípio, foi referido como constrangedor pelo Sr. Luz, que não conhecia as pessoas com quem ia "dividir o mesmo teto". O ambiente hospitalar lhe era hostil, a preocupação da mãe lhe incomodava, até que ele passou a ver um outro lado: o de fazer novos amigos, o fácil acesso ao serviço de saúde (uma vez que o albergue é localizado em frente ao hospital). Hoje, ele diz estar adaptado e que aprendeu a conviver bem com essas modificações. Quinzenalmente vai à Serra ver seus pais e sua filha. Relata que, às vezes, não vai em menor intervalo de tempo, pelo custo da viagem e informa que o custeio com as passagens quinzenais é financiado pelo centro de diálise.

Nos dois primeiros meses do estudo, deslocouse com mais freqüência ao seu lugar de origem, e lá permanecia por alguns dias, faltando até às sessões de diálise. O Sr. Luz justificava dizendo que estava muito preocupado com a gravidez da filha, que assumiria o bebê sem a ajuda do parceiro que tinha se afastado totalmente. Somado a este fato, sua mãe, já idosa, fica muito preocupada quando sua ausência 
ultrapassa uma semana, acreditando ela ter ocorrido "uma coisa ruim" (morrer).

A ocorrência da doença e as limitações provenientes do tratamento alteraram seus valores e estilo de vida. Aquele homem que freqüentava antes, com muita assiduidade, as festas dançantes, os bares, as rodas de amigos, hoje é um espectador assíduo da emergência hospitalar de um hospital de grande porte e único na Região Norte no estado do Ceará preparado para receber clientes em estados críticos. Senta na calçada do albergue ou na sorveteria ao lado e começa a observar o movimento. Conforme informou o Sr. Luz: "Antes eu ia sempre às festas, cheio de amigos e até tomava umas. Mas, agora eu fico na calçada do albergue, gosto de ficar olhando o movimento dos acidentes aí da emergência".

Outra atividade de lazer, segundo o Sr. Luz é caminhar até um posto de gasolina próximo, onde fez amizade com os frentistas, assim como também é amigo dos funcionários da sorveteria. Só não fez muita amizade com o rapaz da funerária (o outro vizinho do albergue ). Comenta que os outros 23 clientes com quem divide o albergue representam uma nova familia, com quem "bate- papo", divide problemas, passeiam. Só uma atividade bastante realizada pelos demais clientes não é dividida pelo Sr. Luz: é o jogo de baralho, uma vez que não sabe jogar e não tem vontade de aprender. E nestes momentos que ele caminha até o posto de gasolina.

Neste cenário, emerge a importância de fatores tecnológicos para o tratamento do cliente que afirma viver porque a hemodiálise existe, ao mesmo tempo que menciona que esta só tem razão de ser como uma etapa do tratamento enquanto aguarda o que acredita ser definitivo e representa seu maior sonho: o transplante renal. O seu conceito de saúde foi expresso por: "é ter força para agüentar esperar o transplante" . E acrescenta ainda: "se Deus quiser eu vou conseguir um rim". Percebe-se aqui a influência do fator religioso bem como dos fatores políticos e legais. A influência da religiosidade apresenta-se como suporte para o enfrentamento da doença, numa esperança de um tratamento que não gere tanta dependência, interpretado muitas vezes como cura e como forma de aceitação do atual momento. Recordamos a influência dos fatores politicos e legais neste contexto, uma vez que as políticas de saúde voltadas para o cliente portador de IRC, ainda privilegiam recursos para as terapias dialiticas (apesar de mesmo neste setor serem precárias e insuficientes ) em relação aos investimentos direcionados aos transplantes de órgãos, que encontram empecilhos relacionados a fatores educacionais, religiosos e sociais quanto à doação de órgãos quer de doadores vivos ou cadáveres.

O fator educacional também foi percebido como impeditivo para compreensão da doença e do tratamento, uma vez que o Sr. Luz atribui a doença às atividades de trabalho desenvolvidas por ele, anteriormente. Questiona que não tem diabetes, nem pressão alta e nem incha muito, então o problema da disfunção renal só "pode ter vindo do fato de ficar muito tempo sentado", acrescenta ele. Os registros do centro identificam como causa básica da doença, uma glomerulonefrite. Outro depoimento que reforça a falta de conhecimento acerca do tratamento é o fato de a dieta alimentar entendida e seguida pelo cliente ser aquela que restringe sal e pimenta.

Sr. Luz desenvolveu alguns mecanismos de como lidar melhor com a doença, em relação ao controle da ingesta hídrica. Ele afirma beber raríssimas vezes ao dia, mas quando bebe, ingere uma quantidade suficiente para saciar a sede.

Chamou-nos atenção as marcas da doença nos braços do Sr. Luz. Eram cicatrizes que, nos dois membros, perfaziam o número de cinco incisões de fistulas arterio-venosas - FAV. Duas delas nunca chegaram a funcionar, uma outra é o atual acesso para terapia hemodialitica e as demais foram "perdidas", sendo que uma destas condicionou a formação de um aneurisma que rompeu no albergue, após Sr. Luz exigir do braço mais do que ele poderia dar: "levantei peso, né... ( sorrisos ) ai o sangue espirrou e corri para emergência, então perdi a fistula". Acrescenta que na época necessitou da inserção de cateter no pescoço (veia jugular interna) para continuar dialisando.

\section{Sistemas de saúde:}

Sistema popular:

$>$ Restrição dietética de sal e pimenta;

$>$ Ingesta de grande quantidade de água, com grande intervalo de tempo;

$>$ Rezacomosuporte de vida;

> Reza para conseguir um transplante;

> Caminha para se distrair,

> A doença é fator impeditivo para o trabalho;

> Parceria com os colegas do albergue;

> Enfrenta a doença sem grandes transtornos;

$>$ Preocupação com as condições financeiras mediante o nascimento do neto;

> Retorno periódico ao ambiente de origem da filha;

> Falta à diálise para ficar com a filha grávida

Sistema profissional:

> Procedimento dialítico, faz-se necessário na busca de um equilíbrio hidro-eletrolitico e na eliminação das escórias nitrogenadas através dos processos de difusão, osmose e ultrafiltração. 
Há necessidade de restrição dietética de potássio, sódio e fósforo, de acordo com as dosagens séricas destes eletrólitos;

$>$ É imprescindivel restrição hídrica, de acordo com a função renal residual;

$>$ Informações, quanto à doença e tratamento, melhoram a compreensão e participação da pessoa no processo de cuidar;

> Ocupação é uma atividade terapêutica que visa minimizar a ansiedade e fatores geradores de estresse propiciando o equilíbrio biopsicosocial;

$>$ Orientação para o autocuidado com a FAV (não permitir verificação da pressão arterial, de temperatura axilar, não comprimir o membro da FAV, não erguer peso), faz-se necessária para preservação da mesma.

$>$ Participação em grupo de auto-ajuda, dividindo com os demais integrantes a experiência e identificando o que é comum a todos bem como o que é particular, onde a solução seja construída a partir da percepção do grupo, minimizando dessa forma as dificuldades encontradas diante a doença e tratamento.

\section{Decisões e ações do cuidado cultural}

As decisões acerca do cuidar deram-se conjuntamente com o Sr. Luz a partir da identificação do seu sistema popular. Buscou-se realizar um plano de cuidados de forma a respeitar suas crenças, valores e modo de vida. A experiência do Sr. Luz foi valorizada durante todo processo.

O enfermeiro, neste modelo, desempenha o papel de articulador do cuidado mediante a identificação do cuidado popular e o conhecimento do cuidado profissional. Conseguimos, assim, manter, negociar e repadronizar alguns comportamentos. O cuidado de enfermagem nesta perspectiva transcultural será benéfica apenas quando os clientes conhecidos pela enfermeira e seus padrões e expressões sejam valorizados como essenciais para a sua sobrevivência.

Durante os encontros, nossa presença era sentida como de pessoa aliada, compartilhando decisões, pensamentos e ações do cuidado. Listamos abaixo as nossas decisões:

\section{Manutenção do cuidado cultural:}

$>$ Restrição dietética de sal;

> Rezacomo suporte de vida;

> Caminha como prática de lazer,

$>$ Parceria com os colegas do albergue;

$>$ Enfrenta a doença sem grandes transtornos;

$>$ Retorno periódico ao ambiente de origem (pais e filha );
Optamos por manter estas ações descritas no sistema popular do Sr. Luz por acreditarmos que elas lhes proporcionam bem-estar e que se apresentam como mecanismos de enfrentamento apreendidos de como conviver com a IRC.

\section{Acomodação do cuidado cultural:}

\section{> Restrição dietética de pimenta;}

> Ingesta de grande quantidade de água, com grande intervalo de tempo;

$>$ Reza para conseguir um transplante;

$>$ Preocupação com a situação econômica, a partir da chegada de mais um membro;

> Observação da emergência como prática de lazer.

As ações negociadas demandaram dos sistemas popular e profissional. Algumas atitudes do Sr. Luz demonstravam o desejo de colaboração, no entanto conversamos sobre a necessidade de adaptá-las. No que se refere à exclusão da pimenta dos hábitos alimentares, por percebermos, através do estudo, que esta aumentava o prazer do paladar de Sr. Luz, resolvemos incluí-la em sua alimentação, em pequena freqüência, uma vez que dessa forma não visualizamos nenhuma contra-indicação. No caso do anseio pelo transplante renal, decidimos que ele continuaria rezando, ao mesmo tempo que procuraria o ambulatório de nefrologia para efetivar a inscrição na lista dos que aguardam um doador cadáver. E dessa forma procedeu-se com os demais.

\section{Repadronização do cuidado de enfermagem:}

$>$ A doença é fator impeditivo para o trabalho;

$>$ Sobrecarga de peso no braço da FAV.

Como estas duas ações pareciam repercutir de forma muita negativa no cotidiano do Sr. Luz, propusemos revê-las em sua totalidade. O Sr. Luz afirmou que cuidará mais ativamente do seu acesso vascular e quanto à ociosidade sentida passou a se engajar num projeto desenvolvido pelos LIONS CLUBE (ONG) em parceria com o centro de diálise.

\section{Cuidado de enfermagem culturalmente congruente}

A utilização da teoria transcultural, como embasadora da ação do cuidar, permitiu-nos uma maior aproximação com o Sr. Luz e conhecimento de seus valores e visão do mundo; principalmente quando relacionada à IRC e forma de conduzi-la. Percebeu-se 
que o Sr. Luz apresenta um modo particular de cuidarse, o que Leininger denominou de diversidade cultural do cuidado.

Vê-se, assim, a importância do conhecimento da estrutura sócio- cultural dos clientes por nós assistidos. Na pessoa em estudo, faz-se necessário um maior envolvimento da equipe de saúde, particularmente da enfermagem, no desenvolvimento de ações educativas culturalmente congruentes para que o Sr. Luz conheça melhor sua doença e tratamento.

\section{CONSIDERAÇÕES FINAIS:}

A abordagem etnográfica permitiu uma maior aproximação com o sujeito do estudo, permitindo perceber como vivencia seu cotidiano e nos contextos onde as ações acontecem.

Cuidar de pessoa com insuficiência renal crônica, em terapia hemodialítica, baseado no modelo SUNRISE proposto por Leininger, foi relevante mediante a necessidade de intervir diante de comportamentos que aos olhos profissionais expressavam não adesão. Acreditamos que os cuidados negociados e repadronizados só foram possiveis por que seguimos todos os passos do cuidar indicado pela autora, e que todo o processo de decisão foi uma ação conjunta entre pesquisadores e sujeito do estudo. Ressalte-se, ainda, que a relação enfermeira e sujeito é anterior a este estudo de caso e que consideramos esta relação fator imprescindivel para o êxito do mesmo.

\section{REFERÊNCIAS BIBLIOGRÁFICAS}

(1) Ianhez LE. Principais problemas do tratamento do paciente renal crônico no Brasil. Âmbito Hospitalar. 1995; 7(78): 47-50.

(2) Sociedade Brasileira de Nefrologia. Tratamento dialitico. Inf Soc Bras Nefrol. 1998 jul; Editorial.

(3) Riella MC. Princípios de nefrologia e distúrbios hidroeletroliticos. $3^{\circ} \mathrm{ed}$. Rio de Janeiro: Guanabara Koogan, 1996.

(4) Brenner MB. Principles of internal medicine. $12^{\circ}$ ed. New York: McGraw-Hill; 1991.

(5) Cesarino CB, Casagrande LDR. Paciente com insuficiência renal crônica em tratamento hemodialftico: atividade educativa do enfermeiro. Rev Lat Am Enferm 1998; 6(4):31-40.

(6) Saes SC. Alterações comportamentais em renais crônicos. Nursing (ed. brasileira) 1999; 2(12): 17-19.

(7) Leininger MM. Culture care diversity \& universality: a theory of nursing. New york: National League for Nursing Press, 1991-
(8)George JB. Teorias de enfermagem: os fundamentos para a prática profissional. 4ed. Porto Alegre: Artes Médicas; 2000.

(9)Leininger MM. Teoria do cuidado transcultural: diversidade e universalidade.[Apresentado ao $1^{\circ}$ Simpósio Brasileiro de Teoria de Enfermagem; 1985 mai 20-24; Florianópolis].

(10) Barreto JOC. Tudo mudou com a doença: uma visão cultural da família. [dissertação] Fortaleza(CE): Universidade Federal do Ceará; 1998.

(11) Trivinõs ANS. Introdução à pesquisa em ciências sociais: a pesquisa qualitativa em educação. São Paulo: Atlas; 1987.

(12)Ludke M, André MEDA. Pesquisa em educação: abordagens qualitativas. São Paulo: Editora Pedagógica e Universitária; 1986.

(13) Polit DF, Hungler BP. Fundamentos de pesquisa em enfermagem. 3ed. Porto Alegre: Artes Médicas, 1995.
Artigo recebido em 21111100

Artigo aprovado em 09/05/02 